\title{
Sleep Position and Stillbirth - Is it Time to Change Sleep Practices?
}

\author{
Meera Simoes, ${ }^{1}$ Ghada Bourjeily² and Fidaa Shaib ${ }^{3}$ \\ 1. Alpert Medical School of Brown University, Rhode Island Hospital, Providence, RI, USA; 2. Alpert Medical School of Brown University, \\ The Miriam Hospital, Providence, RI, USA; 3. Baylor College of Medicine, Houston, TX, USA
}

DOI: https://doi.org/10.17925/ERPD.2019.5.1.14

$\mathrm{R}$ ecent retrospective case control studies have linked maternal going-to-sleep position with stillbirth, a devastating pregnancy outcome. While this debate is reminiscent of data surrounding infant sleep position and sudden infant death syndrome, underlying biological processes are certainly distinct. Maternal haemodynamics and upper airway patency in the supine position offer biological plausibility for this association. However, currently available data have significant limitations and leave many questions unanswered. Addressing these limitations in the future with prospective cohorts will likely prove difficult given the overall low relative prevalence of stillbirths.

\section{Keywords}

Sleep position, supine sleep, stillbirth, pregnancy

Disclosure: Meera Simoes, Ghada Bourjeily and Fidaa Shaib have no conflicts of interests to declare.

Acknowledgments: The authors acknowledge Beth Hott for her assistance with the manuscript.

Review Process: This article is a short opinion piece and has not been submitted to external peer reviewers.

Compliance with Ethics: This article is an opinion piece and does not report on new clinical data, or any studies with human or animal subjects performed by any of the authors.

Authorship: The named authors meet the International Committee of Medical Journal Editors (ICMJE) criteria

for authorship of this manuscript, take responsibility for the integrity of the work as a whole, and have given final approval for the version to be published.

Received: 29 August 2019

Published Online: 24 September 2019

Citation: European Respiratory \&

Pulmonary Diseases. 2019;5(1):14-5

Corresponding Author: Fidaa Shaib, Baylor College of Medicine, 7200 Cambridge Street, Houston, TX 77030. E: shaib@bcm.edu

Support: Ghada Bourjeily is funded by NIHCD (R01 HD-078515) and NHLBI (R01 HL-130702).
As we spend about a third of our lives sleeping, sleep has been linked to many health outcomes during the past few decades, ${ }^{1}$ such as cardiovascular ${ }^{2}$ and metabolic health, cognition, ${ }^{3}$ and even mortality. ${ }^{4}$ Sleep in pregnancy has also emerged as an area of interest in relation to pregnancy outcomes for both mother and foetus. However, most of the data in this population have been about sleep disturbances, sleep quality and duration, ${ }^{5-8}$ and sleep disordered breathing. ${ }^{9-13} \mathrm{~A}$ recent, yet limited body of literature has focused on sleep position and its potential connection with an adverse pregnancy outcome, stillbirth.

Information resources such as books and websites advise patients to sleep in the left lateral position, with 'better blood flow' being the main justification for such recommendation. It is well established that in labour, the supine position is associated with decreased foetal oxygenation. ${ }^{14}$ Recent retrospective data have linked going to sleep in the supine position with an increase in the risk for stillbirths. ${ }^{15-21}$

Stillbirth is a devastating complication. While there are well-established risk factors for stillbirth, a large percentage of stillbirths occurs without obvious risk factors, making the association with sleep position an attractive possibility, as it may be a potentially modifiable risk factor. A recent study, an individual patient data meta-analysis of all available data by Cronin et al., has examined sleep position data from nearly 800 stillbirths and over 2,000 controls. ${ }^{22}$ The study showed a 2.6-fold increase in the risk of stillbirths in women going to sleep in the supine position compared with women going to sleep in the left decubitus position. None of the other non-supine goingto-sleep positions was associated with an increased risk. The study also showed no significant interactions between sleep position and any of the prespecified indicators of foetal vulnerability.

It would be very exciting to identify sleep position as an established risk factor for stillbirths given its potential for modification. There is certainly biological plausibility for the increased risk of stillbirths in the supine position given haemodynamic changes in pregnancy, and increased tendency for potential for upper airway collapsibility in this position. A recent imaging study performed on women in the third trimester of pregnancy demonstrates significant reductions in both cardiac output and blood flow in the inferior vena cava in the supine position compared to the left lateral position. ${ }^{23}$ It is also possible that the link between the supine position and the occurrence of stillbirths may relate to airway collapsibility in this position, and the occurrence of sleep disordered breathing. The upper airway collapsibility contributing to obstructive sleep disordered breathing is a result of a complex interplay of static (anatomy) and dynamic (neuromuscular network and airflow) factors. The propensity of the upper airway to collapse is highest at the level of the oropharynx (retropalatal and retroglossal). ${ }^{24}$ Critical closing pressure, the minimal intraluminal airway pressure required to keep the collapsible segment open, is unaffected by sleep stage but is higher in the supine compared to the lateral position. ${ }^{25}$ The minimal cross-sectional area of the retroglossal space is increased significantly when body position is shifted from supine to lateral. ${ }^{26}$ Upper airway narrowing is exaggerated during pregnancy and more so in the supine position due to upper airway oedema, decreased lung volumes and weight gain. ${ }^{27,28}$ 
The available data on sleep position and pregnancy need to be interpreted in the light of some significant limitations, methodological and otherwise. 1) Case control design where going-to-sleep position data were obtained after the occurrence of stillbirth may have potentially led to recall bias. ${ }^{16,18-22} 2$ 2) Sleep position data is all based on self report rather than objective documentation. . $1,18-22$ In the case-control studies, women with a recent stillbirth were asked to recall their sleep position prior to the occurrence of the stillbirth. 3) Though there is a good agreement between self-reported going-to-sleep position and video monitoring, kappa $0.52,{ }^{19}$ stillbirth was linked to the going-to-sleep position and not to the duration of time spent in that position on a given night. Though a prior study suggests that pregnant women are likely to maintain their going-to-sleep position for the next 70 minutes on average, the authors did not report whether women spent the majority of their sleep time in that position. ${ }^{29}$ Hence, it is possible that the time spent in a given position during bedtime may be a more relevant variable to examine than the going-to-sleep position. 4) The lack of specificity of the association of supine sleep position with stillbirths. A recent internet-based study had shown an association of a history of stillbirth with multiple sleep variables such as waking up on the right side, not waking up more than once at night and daily napping, but not with supine sleep. ${ }^{19}$ The association of stillbirth with these sleep variables cannot be explained with the same haemodynamic changes or upper airway collapsibility as supine sleep, and hence show lack of specificity and raise questions about a causal association with supine sleep. 5) Large population-based studies do not support the association of a diagnosis of obstructive sleep apnoea with the occurrence of stillbirth,11,30-32 making upper airway collapsibility as a potential mechanistic pathway behind the association less plausible.
Hence, recommendations based on these data would need to be interpreted and disseminated very carefully as it is common for patients to experience self-blame following an unexplained stillbirth. Obstetricians usually approach this issue with great sensitivity, and any recommendations would need to be given without triggering anxiety in future pregnancies. Furthermore, while the 'Back to Sleep' modification of sleep position in infants has resulted in a reduction in the number of cases of sudden infant death syndrome, the implementation of sleep position changes in adults who have the capability to change positions multiple times in their sleep is not without challenges. Adherence to positional therapy in pregnant women also appears to be worse than non-pregnant adults, ${ }^{33}$ given the various mechanical changes that occur in a normal pregnancy, and make sleep as fragmented and disrupted as it is.

In summary, the data on sleep position and stillbirths is very intriguing; however, many questions remain to be answered before recommendations and interventions to modify sleep position could be incorporated into routine practice. What is the impact of the going-tosleep position on total bed time spent in that position? What about the waking-up sleep position? Are there differences between early and late stillbirth given the potentially more profound haemodynamic changes later in pregnancy? Is there a potential for maternal adaptation to supine sleep? Is there a correlation between maternal supine hypotension syndrome and stillbirth? The complexity of stillbirth and the fact that it is a rare event should not deter the scientific community from working towards recommendations that could decrease the stillbirth rate, though it would be unlikely that randomised trials aimed at reducing the rates of stillbirth could be performed. $\square$
1. Matsumoto T, Tabara Y, Murase $K$, et al. Association between sleep disturbance and nocturnal blood pressure profiles by linear mixed model analysis: the Nagahama study. Sleep Med. 2019;61:104-9.

2. Genuardi MV, Ogilvie RP, Saand AR, et al. Association of short sleep duration and atrial fibrillation. Chest. 2019:156:544-2.

3. Henry A, Katsoulis M, Masi S, et al. The relationship between sleep duration, cognition and dementia: a Mendelian sleep duration, cognition and dementia: a Mendelian

4. Wallace ML, Buysse DJ, Redline S, et al. Multidimensional sleep and mortality in older adults: a machine-learning sleep and mortality in older adults: a machine-learning
comparison with other risk factors. J Gerontol A Biol Sci Med SCI. 2019:74:1903-9.

5. Loy SL, Cheung YB, Cai S, et al. Maternal night-time eating and sleep duration in relation to length of gestation and preterm birth. Clin Nutr. 2019. doi: 10.1016/j.clnu.2019.08.018. [Epub ahead of print].

6. Christian LM, Carroll JE, Porter K, Hall MH. Sleep quality across pregnancy and postpartum: effects of parity and race. Sleep Health. 2019:5:327-34.

7. Redfern KM, Hine RS, Hollands $\mathrm{HJ}$, et al. Objectively measured sleep duration and plasma glucose values following an oral glucose tolerance test amongst pregnant women with obesity in the UK. Sleep Med. 2019:59:110-3.

8. Okun ML, Tolge M, Hall M. Low socioeconomic status negatively affects sleep in pregnant women. $J$ Obstet Gynecol Neonatal Nurs. 2014:43:160-7.

9. Bourjeily G, Chambers A, Salameh M, et al. Anthropometric measures and prediction of maternal sleep-disordered breathing. J Clin Sleep Med. 2019;15:849-56.

10. Link BN, Eid C, Bublitz MH, et al. Pulse transit time in pregnancy: a new way to diagnose and classify sleep disordered breathing? Sleep. 2019;42:pii:zszo22.

11. Bourjeily G, Danilack VA, Bublitz MH, et al. Obstructive sleep apnea in pregnancy is associated with adverse maternal Outcomes: a national cohort. Sleep Med. 2017:38:50-7.
12. Dominguez JE, Grotegut CA, Cooter $\mathrm{M}$, et al. Screening extremely obese pregnant women for obstructive sleep apnea. Am J Obstet Gynecol. 2018;219:613 e611-3.

13. Wilson DL, Walker SP, Fung AM, et al. Sleep-disordered breathing in hypertensive disorders of pregnancy: a BMImatched study. I Sleep Res. 2018;27:e12656.

14. Carbonne B, Benachi A, Leveque ML, et al. Maternal position during labor: effects on fetal oxygen saturation measured by during labor: effects on fetal oxygen saturation me
pulse oximetry Obstet Gynecol. 1996:88:797-800.

15. Lakshmi ST, Thankam U, Jagadhamma P, et al. Risk factors for still birth: a hospital based case control study. Int J Reprod Contracept Obstet Gynecol. 2017;6:970-4.

16. McCowan LME, Thompson JMD, Cronin RS, et al. Going to sleep in the supine position is a modifiable risk factor fo late pregnancy stillbirth; Findings from the New Zealand multicentre stillbirth case-control study. PloS One. 2017;12:e0179396

17. Owusu JT, Anderson FJ, Coleman J, et al. Association of maternal sleep practices with pre-eclampsia, low birth weight, and stillbirth among Ghanaian women. Int J Gynaecol Obstet 2013;121:261-5.

18. Stacey T, Thompson JM, Mitchell EA, et al. Association between maternal sleep practices and risk of late stillbirth: a casecontrol study. BMJ. 2011:342:d3403

19. O'Brien LM, Warland J, Stacey T, et al. Maternal sleep practices and stillbirth: Findings from an international case-control study. Birth. 2019;46:344-54.

20. Heazell A, Li M, Budd J, et al. Association between materna sleep practices and late stillbirth - findings from a stillbirth case-control study. BJOG. 2018;125:254-62

21. Gordon A, Raynes-Greenow C, Bond D, et al. Sleep position fetal growth restriction, and late-pregnancy stillbirth: the Sydney stillbirth study. Obstet Gynecol. 2015;125:347-55.

22. Cronin RS, Li M, Thompson JMD, et al. An individual participant data meta-analysis of maternal going-to-sleep position, interactions with fetal vulnerability, and the risk of late stillbirth.
EClinicalMedicine. 2019;10:49-57.

23. Humphries A, Mirjalili SA, Tarr GP, et al. The effect of supine positioning on maternal hemodynamics during late pregnancy. J Matern Fetal Neonatal Med. 2019;32:3923-30.

24. Kubin L. Neural control of the upper airway: respiratory and state-dependent mechanisms. Compr Physiol. 2016;6:1801-50

25. Ong JS, Touyz $G$, Tanner $S$, et al. Variability of human upper airway collapsibility during sleep and the influence of body posture and sleep stage. J Sleep Res. 2011:20:533-7.

26. Kim WY, Hong SN, Yang SK, et al. The effect of body position on airway patency in obstructive sleep apnea: CT imaging analysis. Sleep Breath. 2019;23:911.

27. Izci B, Vennelle M, Liston WA, et al. Sleep-disordered breathing and upper airway size in pregnancy and post-partum. Eur Respir J. 2006;27:321-7.

28. Izci B, Riha RL, Martin SE, et al. The upper airway in pregnancy and pre-eclampsia. Am J Respir Crit Care Med. 2003; 167:137-40

29. Mclntyre JP, Ingham $\mathrm{CM}$, Hutchinson BL, et al. A description of sleep behaviour in healthy late pregnancy, and the accuracy of self-reports. BMC Pregnancy Childbirth. 2016;16:115.

30. Louis JM, Mogos MF, Salemi JL, et al. Obstructive sleep apnea and severe maternal-infant morbidity/mortality in the United and severe maternal-infant morbidity/mortait

31. Bin YS, Cistulli PA, Ford JB. Population-based study of sleep apnea in pregnancy and maternal and infant outcomes. I Clin Sleep Med. 2016;12:871-7.

32. Spence DL, Allen RC, Lutgendorf MA, et al. Association of obstructive sleep apnea with adverse pregnancy-related outcomes in military hospitals. Eur J Obstet Gynecol Reprod Biol. 2017;210:166-72.

33. Warland J, Dorrian J, Kember AJ, et al. Modifying maternal sleep position in late pregnancy through positional therapy: a feasibility study. J Clin Sleep Med. 2018;14:1387-97. 